\title{
CASE STUDY: BIM PROTOCOL FOR SKANSKA (CZECH REPUBLIC)
}

\author{
Patrik Kvirenc ${ }^{1}$, Robert Bouska ${ }^{2}$ \\ ${ }^{1}$ Skanska, Krizikova 682/34a, 18600 Prague, Czech Republic \\ ${ }^{2}$ CTU in Prague, Faculty of Civil Engineering, Department of Construction Management and \\ Economics, Thakurova 7, Prague, 166 29, Czech Republic, robert.bouska@fsv.cvut.cz
}

\begin{abstract}
The research paper introduces the problems of technical support of a model in projects in the area of BIM. Planning Requirements (BIM protocol) describe the technical preparedness of models, data repletion, information sharing, communications and other processes in construction projects. This BIM protocol was developed for Skanska Inc. It consists of several parts, which are described in the article. At the introduction Skanska Inc. is presented together with its position in the area of BIM in the Czech market. The research analyzed the document itself, including its annexes. Another section is devoted to the importance of BIM protocol in project management of company Skanska. The document was prepared in cooperation with Skanska Inc. It applies only to commercial and residential projects in the area of building construction.
\end{abstract}

\section{Keywords}

BIM (Building Informaton Modeling), BIM protocol, data structure, project management, model

\section{JEL Classification}

L24 Contracting Out; Joint Ventures; Technology Licensing

DOI: $\underline{\text { https://doi.org/10.14311/bit.2017.01.02 }}$

Editorial information: journal Business \& IT, ISSN 2570-7434, CreativeCommons license (c) (i) published by CTU in Prague, 2017, http://bit.fsv.cvut.cz/ 


\section{Introduction}

\section{BIM in Skanska CZ}

Skanska Inc. belongs to leaders and promoters of BIM in the Czech and Slovak Republics. It is a founding member of $C z B I M$ which, through this initiative, aims to extend knowledge in technical community. It also cooperates with universities to support teaching throughout the country.

Historically, Skanska is the first company in the Czech Republic, which has had a building in the area of BIM. Within built constructions, the company still relies on their internal clients Skanska Property Czech Republic Ltd. and Skanska Reality Inc.

The Figure 1 shows historical evolution of BIM projects within the company:

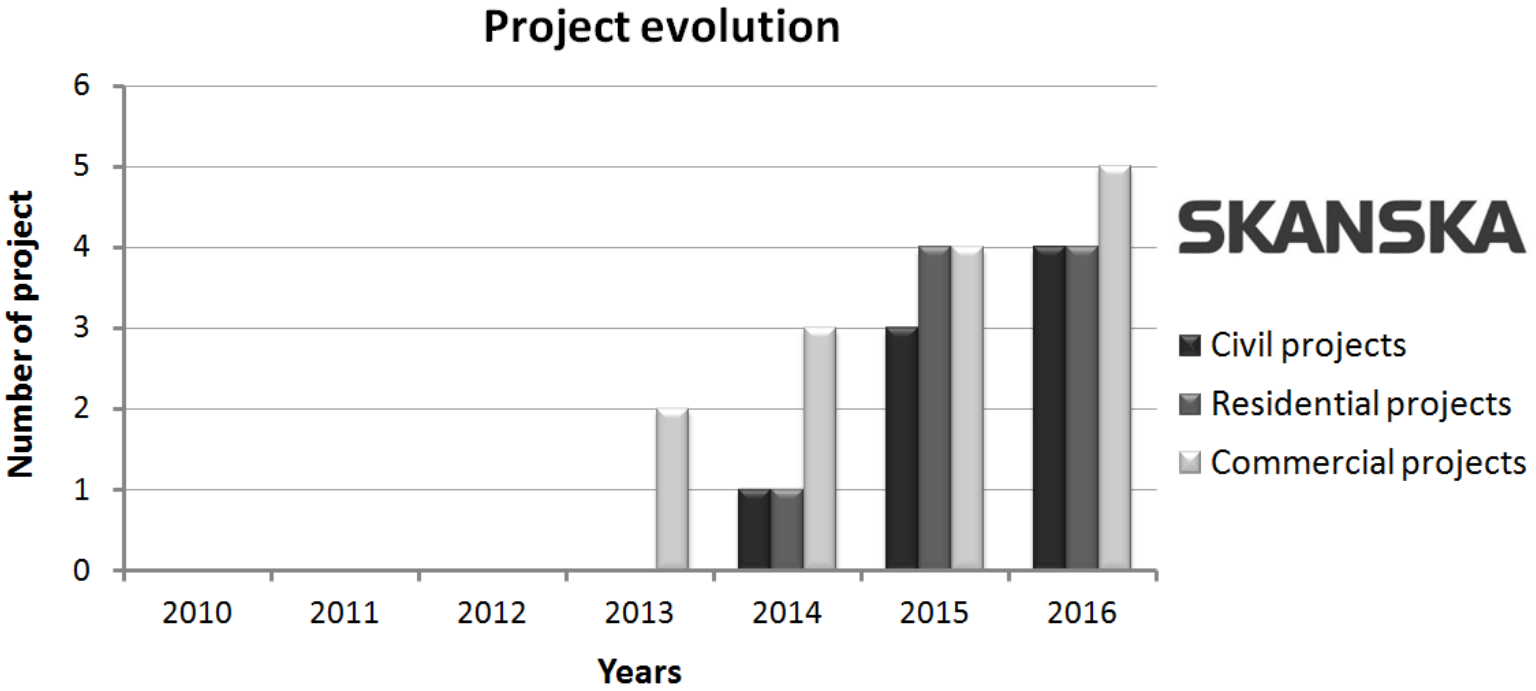

Figure 1: Evolution of BIM projects at Skanska (source: authors)

The period from 2010 to 2012 served to collect available data, knowledge and experience, especially from abroad, where Skanska has a strong base of BIM in the other business units namely from Great Britain, USA, Sweden, Norway or Finland.

During the previous period, first projects have already created subconscious knowledge of standards for the designing in the area of BIM. Based on BIM summits which Skanska organizes for all of its business units, therefrom Czech Skanska has obtained some contacts, that contributed to the idea of making its own standards.

\section{Research}

\section{BIM protocol introduction}

The BIM protocol which was created in cooperation with Skanska CZ is an internal document providing contractual conditions of individual projects in building construction within BIM models. Along with other documents [1], it is crucial for successful adoption of BIM in any company. The document secures technical correctness of the models plus requirements for communication, information sharing and repletion model. The main attachment is a data structure. The structure describes individual parts/components of the building by assigned parameters specifying their properties during the whole life cycle of the project. The scope of information also depends on the 
phase of the project. Another important attachment is BEP. BIM Execution Plan is a set of basic information that describes the project, schedule and stakeholders. This attachment contains BIM goals that are set and agreed by the investor and the contractor of the project.

Generally, BIM protocol gives a complex overview of project's (model's) information and rights and obligations of participants in the construction process are derived from it. It is crucial part of overall BIM adoption, along with other methods [2].

\section{BIM protocol analysis}

BIM protocol is divided into several chapters:

- Introduction

- Basic principles

- Formats and outputs

- BIM modeling

- Facility management

- Green BIM

- Communication

Introduction explains the necessity and importance of the document in methodology and standardization of BIM projects. The position of a BIM coordinator, who is responsible for project documentation and BIM model, is also described there.

Basic principles include general information about modeling, software requirements (Skanska Inc. prefer software from Autodesk - Revit and Navisworks), phasing of project documentation (six phases) and setting up basic information and goals of project (BEP).

The direct output from a 3D model is 2D documentation according to applicable standards in the Czech Republic. The BIM coordinator has responsibility for the project documentation. BIM coordinator controls, distributes and manages the project documentation and 3D model.

BIM modeling is the main technical part. It is based on the previous general requirements for the designing. It describes difference between Level of Detail (graphic part) and Level of Development (information part). Mainly, it contains the requirements for the design and data structure of BIM models. Furthermore, it contains basic classification of the model, parameters of elements, software formats, QTO requirements, process of control, sharing model, etc.

FM is set up for the area of commercial buildings. Data structure of components for the operational phase includes specific requirements for CAFM software Alstanet, which is used by Skanska Facility Ltd. Outputs from the model forms a DWG drawings and tables with information in XLS format, which is compatible with CAFM software.

The requirements for the area of Green BIM specify the information in the model that will be then used for BREEAM and LEED certification. The chapter of Green BIM is at the very beginning and more detailed elaboration will be in the next version of the document.

Chapter communication contains BIM protocol approval from stakeholders and description (form) of communication between them.

BIM protocol attachments are:

- Data structure

- BEP (BIM Execution Plan)

- QTO requirements

- The types of areas and rooms for FM 


\section{BIM protocol in project management of Skanska CZ}

BIM protocol is a strategic document for project management in the area of BIM projects. Ideally, author of a BIM Protocol is an investor, who, with the help of designer and general contractor, completes the requirements for a particular project.

Figure 2 shows passage of contract from the perspective of a general contractor:

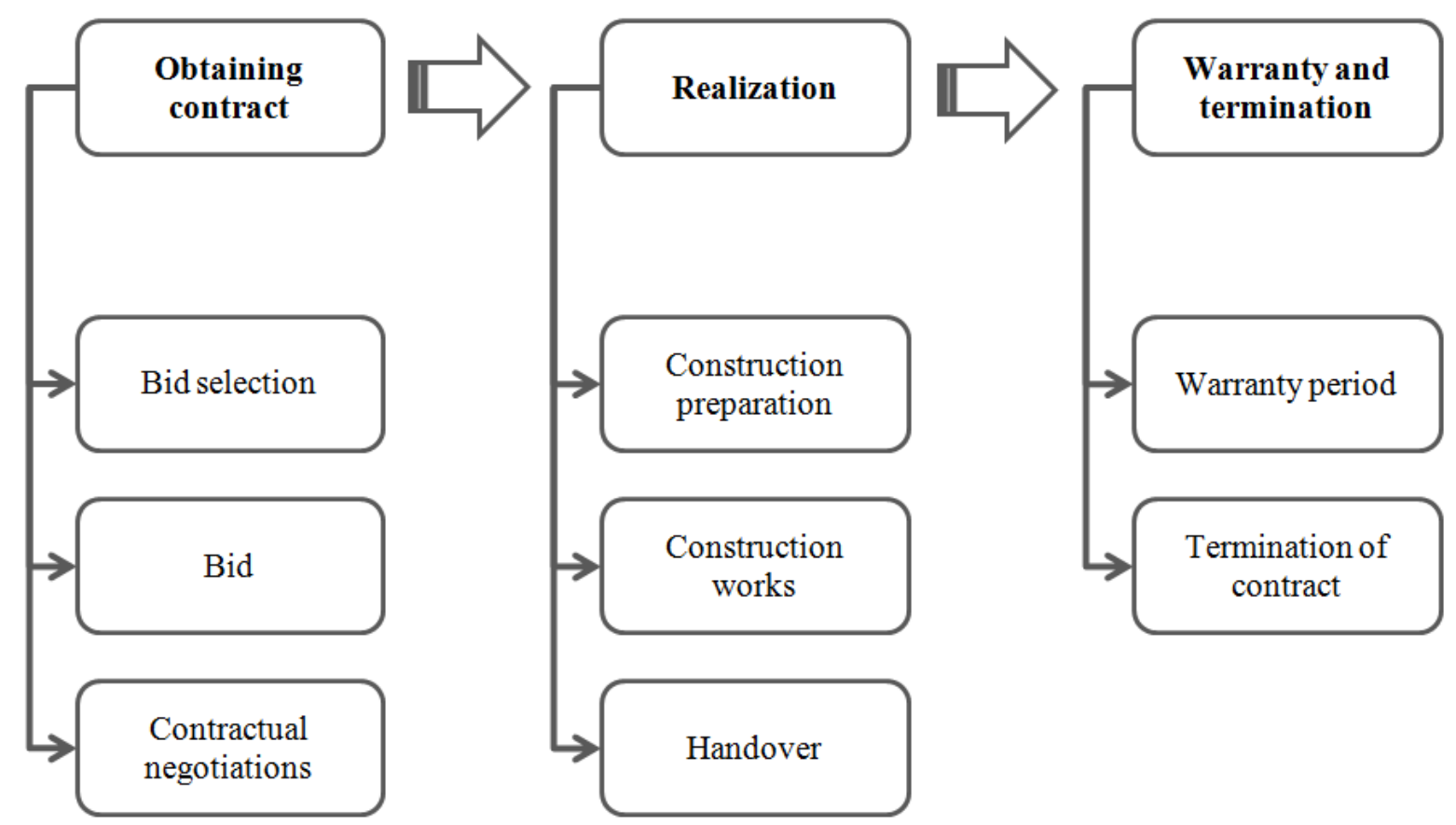

Figure 2: Project management - general contractor (source: authors)

From the perspective of a general contractor, the BIM protocol appears during the contractual negotiations. Contractual negotiations lead to the approval of rights and responsibilities among stakeholders. Another part is to determine objective BIM goals and how to achieve them. These goals and the whole BIM protocol are obligatory for the general contractor, especially in the area of realization. General contractor fulfills the function of supervisory authority to the planner/architect and is responsible for achieve the stated goals.

In the collaboration with internal investors Skanska Property Czech Republic Ltd. and Skanska Reality Inc. BIM protocol is currently being tested in project management. 


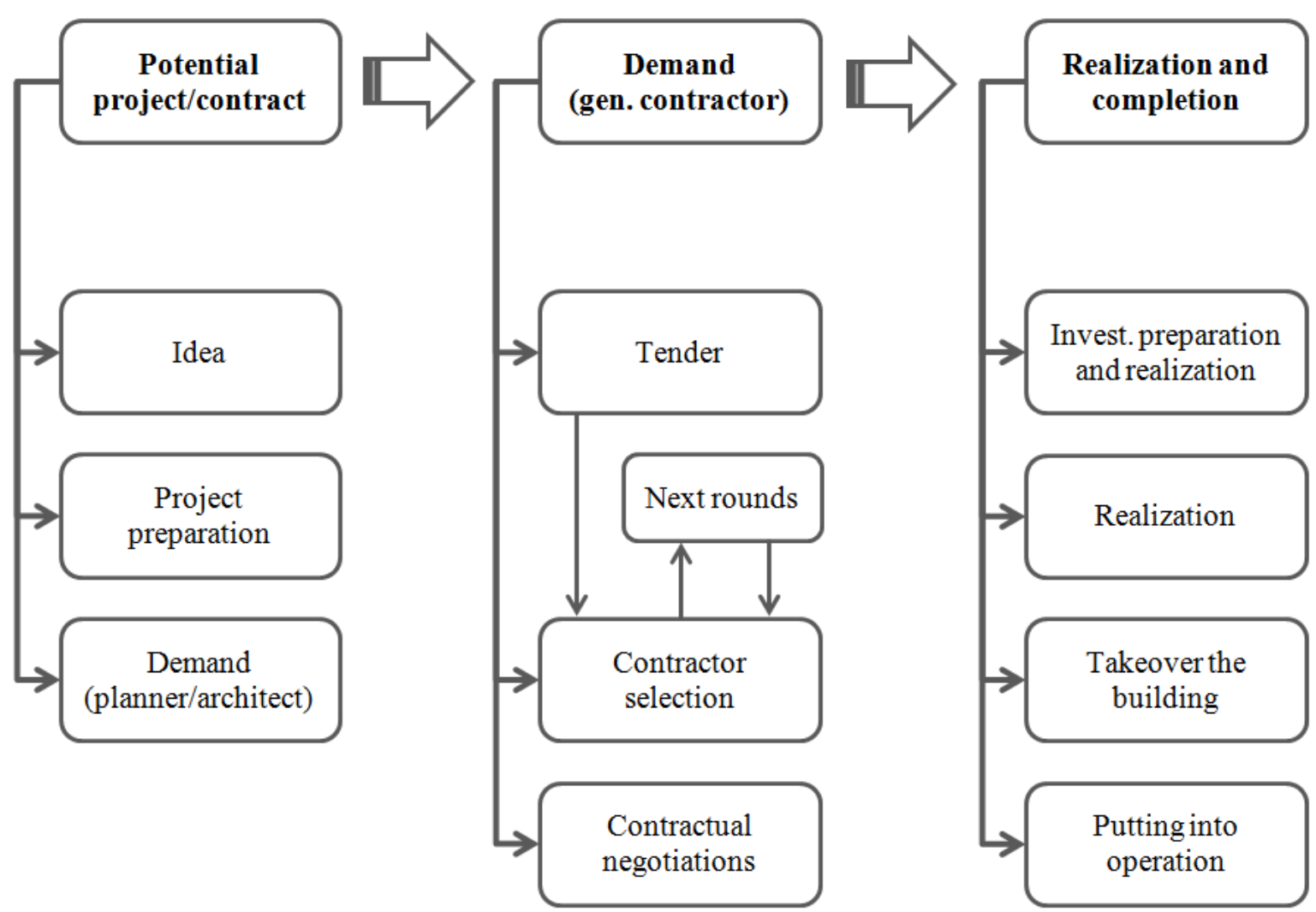

Figure 3: Project management - investor (Source: own)

From the investor's perspective, the BIM protocol enters the project management much sooner. Team of architects must be familiar with the requirements for the design in BIM in the beginning of negotiations. BIM Protocol takes into account six phases of the project, from an architectural study to documentation for facility management. The designer has, in terms of project management and in the context of BIM Protocol, the highest responsibility for compliance with the standards and statutes, which stemmed from the document. The investor's work with BIM protocol is ideally only in the preparation phase of the project.

During the other parts of project, investor has, similarly to a general contractor, exclusively controlling function. Investor oversees both the work of the designer and achieving of the set BIM goals within BEP [3].

\section{Conclusion}

BIM protocol was created in cooperation with Skanska $\mathrm{CZ}$ and is currently being tested on the first projects in commercial and residential development. Relevance and effectiveness of the document will be analyzed at the end of the testing projects.

Standardization of the design work is a necessary part of implementation. BIM protocol is one of the tools that supports this idea and creates a basic standard for its implementation. Detailed analysis of the BIM protocol is processed in the diploma thesis: BIM protocol and its importance in construction projects of Skanska a.s.

\section{Acknowledgement}

This work was supported by the Grant Agency of the Czech Technical University in Prague, grant SGS15/132/OHK1/2T/11: Vyhodnocování efektivity výstavbových projektů při použití metodiky BIM 


\section{References}

[1] Sacks, R., Gurevich, U., \& Shrestha, P. (2016). A review of building information modeling protocols, guides and standards for large construction clients. Journal of Information Technology in Construction, 21, 479-503.

[2] Kassem, M., \& Succar, B. (2017). Macro BIM adoption: Comparative market analysis. Automation in Construction, 81, 286-299. doi:10.1016/j.autcon.2017.04.005

[3] Kaiser, J. (2016). Process modeling for BIM. Paper presented at the CESB 2016 - Central Europe Towards Sustainable Building 2016: Innovations for Sustainable Future, 781-788. 